研究速 報

$\mathrm{Si}_{3} \mathrm{~N}_{4}$ 粒子/6061 Al 複合材料の超塑性変形中の空洞に及ぼす強化材体皘含有率の影響

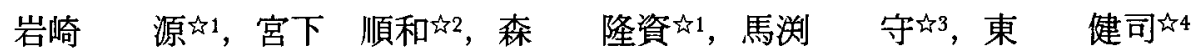

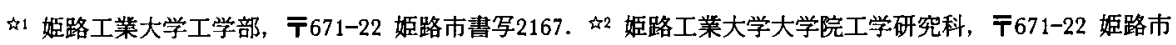

書写2167。名3 古屋工業技術研究所, 厂462 名古屋市北区平手町1-1. 大阪府立大学工学部, 干593 堺市学園町 $1-1$.

\title{
Effect of Reinforcement Volume Fraction on Cavitation of Superplastic $\mathrm{Si}_{3} \mathrm{~N}_{4} / \mathrm{Al}-\mathrm{Mg}-\mathrm{Si}$ Composite
}

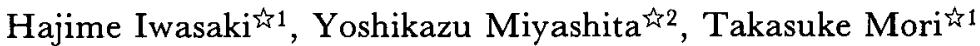

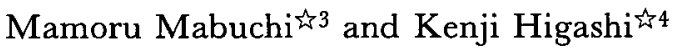

t1 Department of Materials Science and Engineering, Himeji Institute of Technology, 2167 Shosha, Himeji

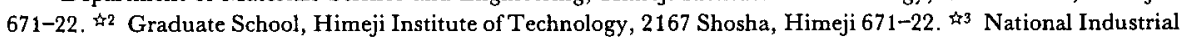
Research Institute of Nagoya, 1-1 Hirate-cho, Kita-ku, Nagoya 462. Department of Mechanical Systems Engineering, University of Osaka Prefecture, 1-1 Gakuen-cho, Sakai 593.

Received January 6, 1995

\section{SYNOPSIS}

The $\mathrm{Si}_{3} \mathrm{~N}_{4}$ particulate reinforced $6061 \mathrm{Al}(\mathrm{Al}-\mathrm{Mg}-\mathrm{Si})$ matrix composite, which included $20 \%$ or $30 \%$ volume fraction of reinforcement, denoted as the $20 \% \mathrm{Vf}$ and the $30 \% \mathrm{Vf}$ respectively, has been prochced by powder metallurgical processing followed by hot extrusion at $773 \mathrm{~K}$ with a rechuction ratio of 100 . The composites exhibited a typical superplastic behavior at a temperature of $848 \mathrm{~K}$ for the $20 \% \mathrm{Vf}$ and $823 \mathrm{~K}$ for the $30 \% \mathrm{Vf}$, and a maximum elongation of $380 \%$ was obtained for the $20 \% \mathrm{Vf}$ at a constant stress of $5 \mathrm{MPa}$ and $734 \%$ was obtained for the $30 \% \mathrm{Vf}$ at a stress of $8 \mathrm{MPa}$ respectively. It has been clarified that these oumposites exhibited cavitation after a superplastic deformation. Cavity volume fractions exponentially increased with increasing strain in both composites. The cavity volume fraction of the $20 \% \mathrm{Vf}$ specimen was less than that of the $30 \% \mathrm{Vf}$ specimen at a strain up to 1.2 . The maximum cavity volume fraction throughout the experiments was $2 \%$ at a strain of 1.5 for the $30 \% \mathrm{Vf}$ specimen. SEM obsevation showed that cavities had always formed at interface between matrix and reinforcements, and the size of most cavities was less than $1 \mu \mathrm{m}$. However, a few large cavities of more than $1 \mu \mathrm{m}$ in a mean diameler also appeared in both specimens in an early stage of straining. The larger cavities were grown rapidly and elongated parallel to the tensile axis with increasing strain which may cause the fracture.

KEY WORDS

Metal matrix composite, superplasticity, high strain rate, cavitation, 6061 Aluminum alloy.

\section{1 緒言}

近年，炭化けい素や窒化けい素をはじめとする各㩖 强化材が製造され，実用アルミニウム合金をマトリッ クスとする複合材料が開発されているが，一般にマト リックス単相材に比べ延性が低く，成形性に欠けるこ とが難点である，しかし，この問題に対し，最近，高 速超塑性を示す襩合材料が開発され”，延性向上と高 速変形の点から注目されている。しかし，この高速超 塑性複合材料においても変形中に内部空洞の発生する ことが分かってきだ!。の内部空洞は，変形啳の複 合材料の强度を考えるとき重要な問題である。

そこで，本研究は高速超塑性を示す $\mathrm{Si}_{3} \mathrm{~N}_{4} / 6061 \mathrm{Al}(\mathrm{Al}-\mathrm{Mg}$-Si)合金複合材料の内部空洞に并 目し，空洞発生状熊を特に窒化けい孳粒子の体樌含有 率の空洞問題に及ぼす影照に重点をおいて調べた。

\section{2 実験方法}

\section{1 複合材料の製造方法}

マトリックス用粉末に6061 Al合金急冷凝固粉末（東 洋アルミニゥム社犁，粒径 $20 \mu \mathrm{m}$ 以下）を用い，強化 材には，直径1 $\mu$ m以下の窒化けい索 $\left(\mathrm{Si}_{3} \mathrm{~N}_{4}\right)$ 粒子(宇部 興産社慗)を用いた Fig.1に複合材料の製作過程のフロー チャートを示す．強化材の体樍含有率が20\%，30\%に なるように，それぞれアルミニウム合金粉末と荎化け い萦粒子を配合し、エチルアルコール中でできるだけ 均一に混合した，次に，エチルアルコール溶媒を蒸発 させ、その湿合轵を真空雾囲気下，圧力390 MPa， $873 \mathrm{~K} て ゙ 1.2 \mathrm{ks}$ 間加圧蜫蛣し，直径 $40 \mathrm{~mm}$ のビレットを 㡀作した. そして，このビレットを温度773Kのもと で押出し比100で押出した.

\section{2 引張試験方法}

押出し材から平行部直径 $2.5 \mathrm{~mm}$ ，平行部長さ $5 \mathrm{~mm}$ の引張試験片を機珹加エで作韾した，定応力試験は応 
$\mathrm{Si}_{3} \mathrm{~N}_{4}$ powder

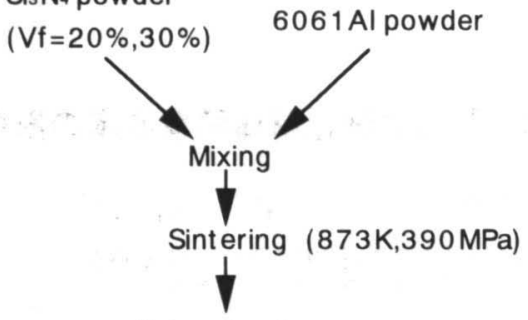

Hot-ext rusion

$(773 \mathrm{~K}$, Ratio=100:1)

Fig.1 Scheme of fabrication procedure for superplastic $6061 \mathrm{Al}$ composites reinforced with $\mathrm{Si}_{3} \mathrm{~N}_{4}$ particulates.

力範囲を $2 \mathrm{MPa} \sim 12 \mathrm{MPa}$ とした。 また試験温度は予備 試験において最適温度として $20 \%$ Vf材は $848 \mathrm{~K}$ 。 $30 \% \mathrm{Vf}$ 材は823K と確定し実験に用いた。いずれも引 張方向は押出し方向に平行とした

2.3 空洞体積率の測定

引張試験後の試験片平行部の空洞量を測定する方法 として，液中秤量による密度测定法を用いた。変形後 の試料の平行部の密度を $\rho_{1}$, 同じ熱履歴のみを受けた 末変形試料の平行部の密度 $\rho_{0}$ を求めると, 以下の式を 用いて空洞体積率が求められる.

空洞体積率 $(\%)=\frac{\rho_{0}-\rho_{1}}{\rho_{0}} \times 100$

湘定に用いた試料は，測定の前に試験片表面の酸化 被膜を1500＃のエメリー紙で研磨除去した. 試料の秤 量には最小目盛り0.01 mgの精度をもつ電子天科を用い, 液体には蒸留水を用いた。

\section{4 組織および空洞の観察}

試料の組織観察には，光学顕 微鏡および透過型電子 顕微鏡(TEM)を用いた。結晶粒径の湘定はTEM観察によ り行なった．また空洞の観察には予め決めたひずみ量 まで変形した試験片から引張軸を含む面を出し、鏡面 研磨後, 高分解能走査型電子顕微鏡(SEM) を用いて行なっ た. 同時に付属の画像処理装置により空洞サイズ分布 を求めた。

\section{3 実験結果および考察}

\section{1 䙉合材料の微細組織}

Fig.2 は熱間押出し後の複合材料の光学顕微鏡組織を $20 \% V f$ 材及び $30 \% V f$ 材について示す. どちらもマトリッ クス中の粒子はきわめて均一に分散していることがわ かる.

Fig.3は複合材料のTEM組織を示す．Fig.3(a)が20\% Vf材の場合で(b)が30\%Vf材の場合である．どちらの 材料とも強化材粒子は大体において結晶粒界に存在し ていることがわかる。これは，押出し過程で，粒子周 囲が再結晶の核サイトとなり，また粒子が再結晶粒の 成長の抑制場所になっていることを暗示している。多 くの写真撮影を行ない求めた平均結晶粒径は2.5 $\mu \mathrm{m}$. $2.1 \mu \mathrm{m}$ であった。

\section{2 複合材料の超塑性引張特性}

Fig.4(a)は真応力とひずみ速度の関係を20\%Vf材は

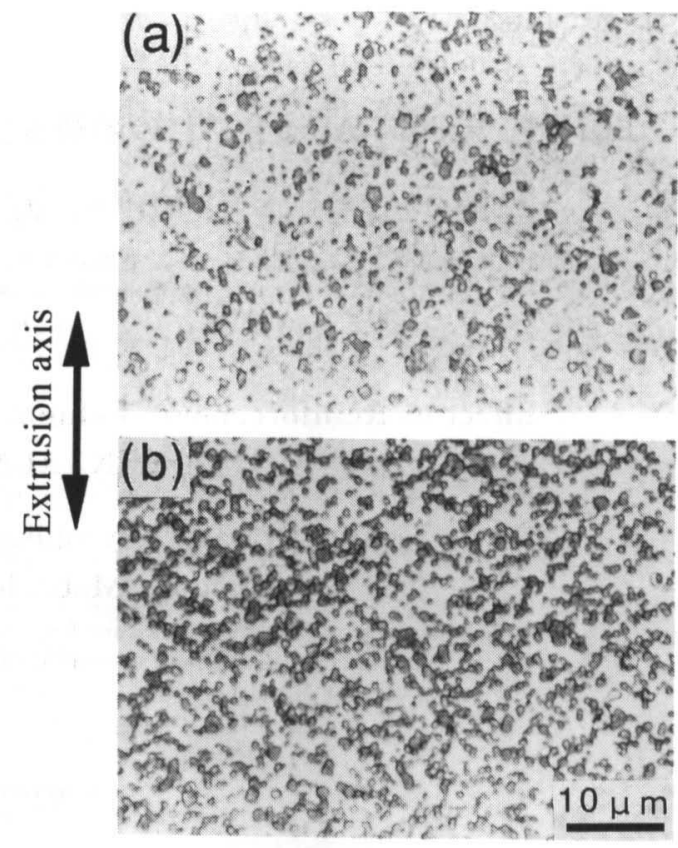

Fig.2 Typical microstructures of the $\mathrm{Si}_{3} \mathrm{~N}_{4} / 6061 \mathrm{Al}$ composites (a) is the $20 \%$ volume fraction of reinforcement and (b) is the $30 \%$ volume fraction of reinforcement.
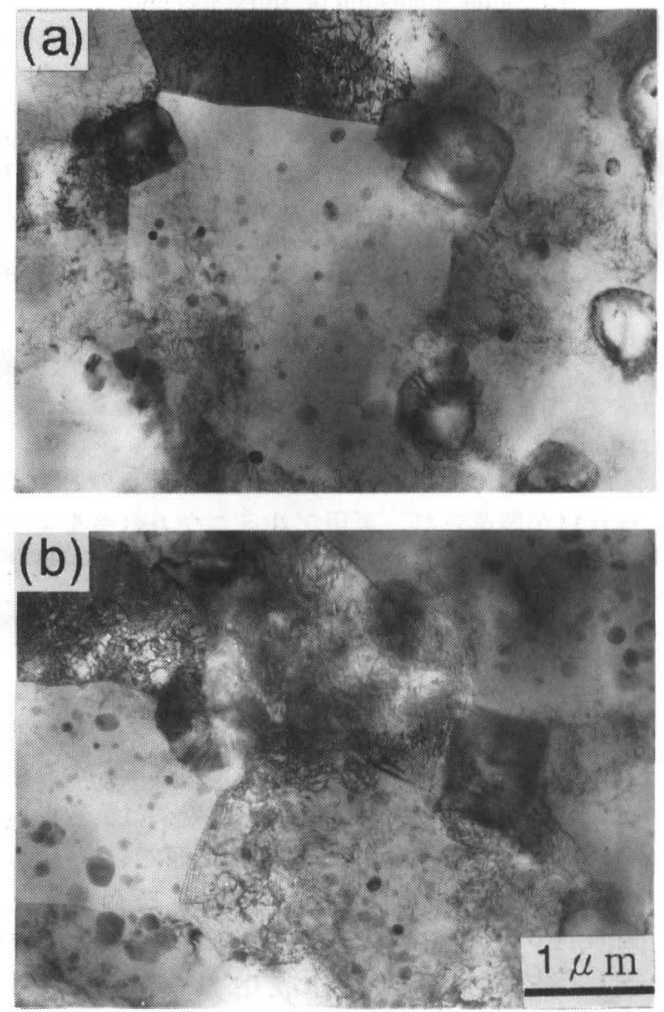

Fig. 3 Transmission electron micrographs of $\mathrm{Si}_{3} \mathrm{~N}_{4} / 6061 \mathrm{Al}$ composites ; (a) is the $20 \%$ volume fraction of reinforcement, and (b) is the $30 \%$ volume fraction of reinforcement. 


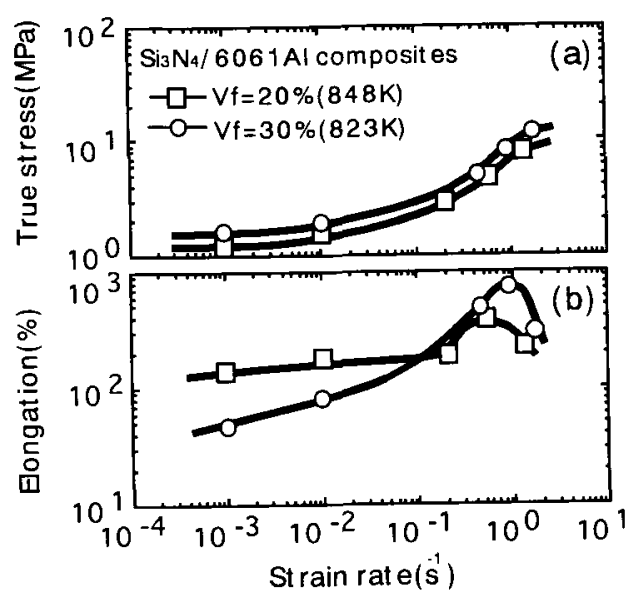

Fig.4 The variations in the stress (a) and elongation to failure (b) as a function of strain rate for the $\mathrm{Si}_{3} \mathrm{~N}_{4} / 6061 \mathrm{Al}$ composite $(\mathrm{Vf}=20 \%, 848 \mathrm{~K}$ and $\mathrm{Vf}=30 \%, 823 \mathrm{~K})$.

$848 \mathrm{KK}$ にいて，30\%Vf材は823Kについて示す Fig.4 (a)から真応力とひずみ速度の傎き(ひずみ速度感 受性指数： $m$ 值)を求めると，両曲線ともひずみ速度が $10^{-1} \mathrm{~s}^{-1}$ から $1 \mathrm{~s}^{-1}$ の間で非常に大きく，この間のm值は ともに0.5以上となっている. またこの典型的な超塑性 举動を示す領域で伸びも大きく(Fig.4b)，20\%Vf材で

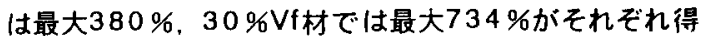
られた，最大伸びの得られる心力およびそのときのひ ずみ速度は前者か流力 $5 \mathrm{MPa}$ ，ひずみ速度 $5.3 \times 10^{-1} \mathrm{~s}^{-1}$ 。 後者が㐫力 $8 \mathrm{MPa}$ ，ひずみ速度 $9.2 \times 10^{-1} \mathrm{~s}^{-1}$ であった。

以上の結果から本研究で用いた複合材料は $20 \% \mathrm{Vf}$ 材， $30 \% \mathrm{Vf}$ 材ともにひずみ速度が0.1 1 $\mathrm{s}^{-1}$ という高速で 超塑性を示すことがわかる.さららに0\%Vf材の方が25 K低温であるにもかかわらず応力、ひずみ速度曲線は 接近していることがわかる．このような高速変形を説 明できる変形䧿構はまだ十分に解明されていないが，

最近, 高速超塑性材料の心力緩和機棰に液相が関与し ているという提案がなされている゙．この钼点から検 討する之，本研究で用いた $\mathrm{Si}_{3} \mathrm{~N}_{4} / 6061$ Al複合材料は。 DSCの結果 ${ }^{4}$ から820K〜830Kの間に局部的に夜相の 出る温度があり，試験温度と比較すると両材とも夜相 の存在が考えられる.液相は種々の合金元素の偏析に 伴う局所的虽解によるものと思われるので，マトリッ クス之強化材粒子の界面や結晶粒界等の欠陥の多い場 所に生じ易いと考えられる.それゆえに強化材含有率 の增加は夜相の発生場所の增加につながり，本実験の ように30\%Vf 材の低温で超塑性特性を示したものと推 察される.

\section{3 空洞体積率による空洞量の評価}

空洞体棈率の湘定は，最も優れた超塑性変形特性を 示す条件（最も大きい伸びが得られた条件），即ち， $20 \% \mathrm{Vf}$ 材は応力 $5 \mathrm{MPa}$ ，温度 $848 \mathrm{~K} ， 30 \% \mathrm{Vf}$ 材は灾力 $8 \mathrm{MPa}$ ，温度 $823 \mathrm{~K}$ で超塑性変形を与えた式験片平行部 について行なった．Fig.5は空洞体稘率と真ひずみとの 関係を示す。両材とも空洞体積率は指数関数的に增加 しており,

$C_{v}=C_{0} \exp (n \varepsilon)$

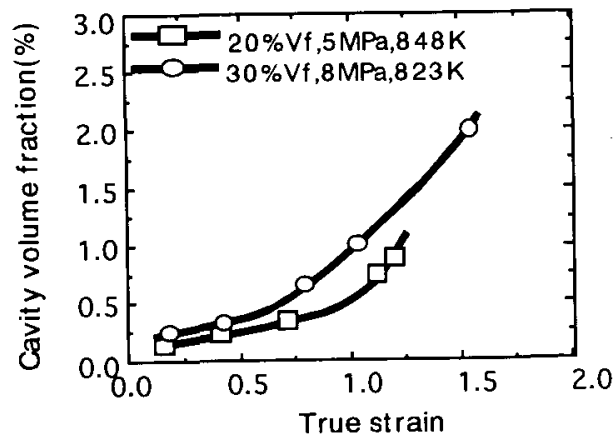

Fig. 5 The variation in the cavity volume fraction as a function of true strain for the $20 \% \mathrm{Vf}$ and the $30 \% \mathrm{Vf}$.

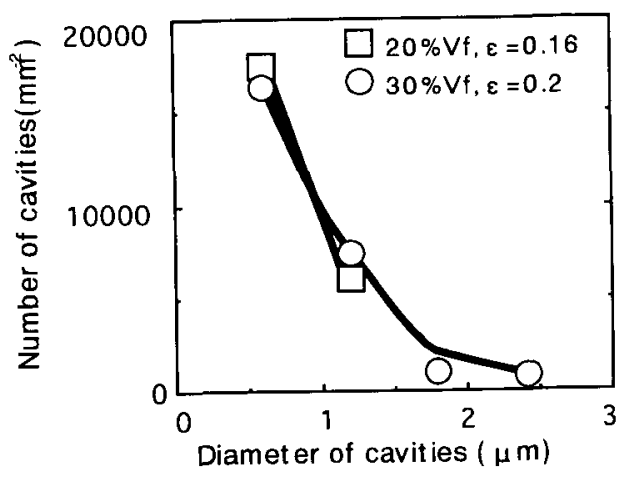

Fig.8 Distribution of cavity sizes for the $\mathrm{Si}_{3} \mathrm{~N}_{4} / 6061 \mathrm{AJ}$ composites $(\mathrm{Vf}=20 \%, 5 \mathrm{MPa}, 848 \mathrm{~K}, \varepsilon=0.16$ and $\mathrm{Vf}=30 \%$, $8 \mathrm{MPa}, 823 \mathrm{~K}, \varepsilon=0.2$ ).

の関係式で表される、ここで 数、nは空洞成長率，にはひずみである。Fig.5におけ るりは20\%Vf材，30\%Vf材で1.7および1.6で殆ど相 逗はない，ひずみが0:2 付近での空洞体皘率は両材亡も 約 $0.2 \%$ ときわめて小さく，最大空洞体㮴率 $20 \%$ Vf 材 の場合、ひずみ約 $1.2 て ゙$ 䄪 $1.0 \% ， 30 \% \mathrm{Vf}$ 材の場合，ひ ずみ約 1.5 で的 $2.0 \%$ \%で增加する．しかし，この增加 割合は一般の合金超塑性材料，例えば，7475Al合金の $\eta=3.0^{5)}$ と比べると，著しく低い值であることがわか る.

\subsection{SEMによる空洞の観察}

Fig.6およびFig.7は，3段階のひずみにおいて钼察さ れた空洞のうち最も大きいものを $20 \% \mathrm{Vf}$ 材と $30 \% \mathrm{Vf}$ 材

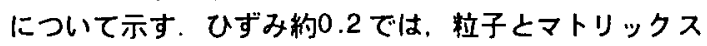
との界面に形成された粒子径相当の空洞が多く見られ る.これは粒子とマトリックスの界面が液相のでき易 い婸所であり，また同時に変形条件によっては空洞の 発生しやすい場所ともなりうるためであると思われる. Fig.8は画像処理装雷により空洞サイズ分布を調べたも のである. 両材とも $1.2 \mu \mathrm{m}$ 以下の空洞数は殆ど同じで ある.しかし、30\%Vf材のほうに2 $\mu \mathrm{m}$ 程度の大きな 空洞が存在することがわかる.この大きさの空洞は核 

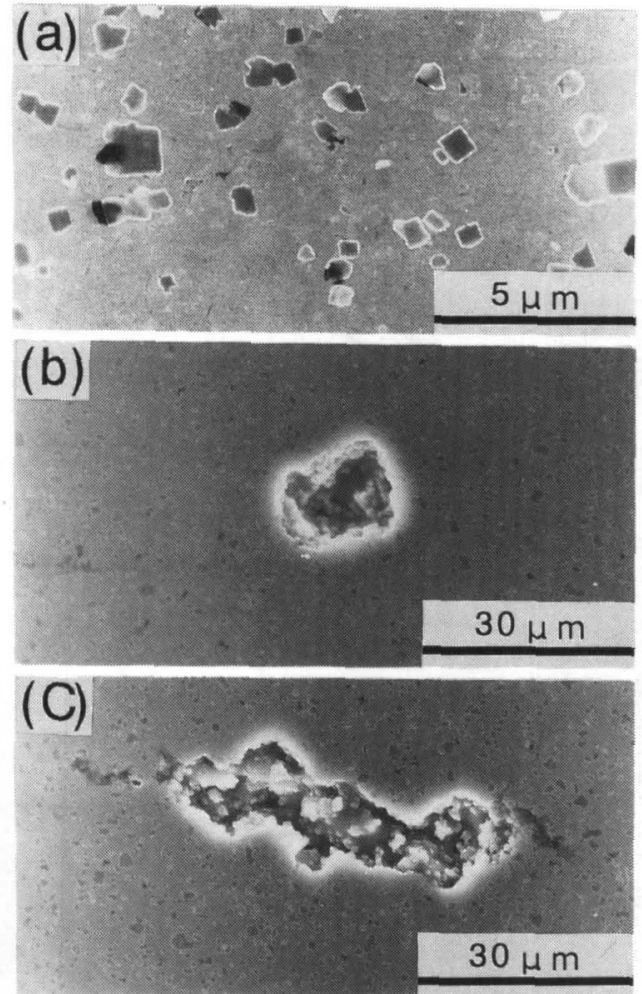

Fig.6 Cavity morphologies in the $\mathrm{Si}_{3} \mathrm{~N}_{4} / 6061 \mathrm{Al}$ composite for the $20 \%$ volume fraction of reinforcement pulled to strains of (a) 0.16 (b) 0.71 and (c) 1.12 at $848 \mathrm{~K}$.

生成した空洞が合体してできたものと推察される。そ れゆえ，強化材粒子の多い30\%Vf材の方か，空洞核廿 イトが多くなり，空洞の合体する確率が增すため大き い空洞の数が多くなるものと思われる.ささらに大きい ひずみ約0.7での空洞は，Fig.6およびFig.7に示すよう に20\%Vf材では，直径15 $\mu \mathrm{m}$ 程度の丸いのに対し， $30 \% \mathrm{Vf}$ 材では引張方向に伸ばされた $40 \mu \mathrm{m}$ 程度のもの が見られるようになる.ひずみ1.0付近では，両材とも 一段と引張方向に伸ばされた空洞を示す.引張方向長 さは20\%Vf材では40 $\mu \mathrm{m}, 30 \%$ 材では70 $\mu \mathrm{m}$ であっ た. 引張試験方向に伸ばされた $10 \mu \mathrm{m}$ 以上の大きい空 洞は，マトリックスの塑性変形に伴って成長した空洞 でいわゆる塑性支配による成長を示すものである。し かし、このように著しく成長した空洞の数は観察した 平䘕部断面全体を通して $20 \% \mathrm{Vf}$ 材で5個 $/ \mathrm{mm}^{2}$ ，30\% $\mathrm{Vf}$ 材では7 個 $/ \mathrm{mm}^{2}$ 程度と少ない。しかし、今後この異 常に成長する空洞の抑制が必要であり，発生条件の解 明を現在行なっている。

\section{4 結 言}

$1.20 \% \mathrm{Vf}$ 材. $30 \% \mathrm{Vf}$ 材ともに空洞体積率はひずみの 增加に伴って指数関数的に增加する. 空洞体樻率は20
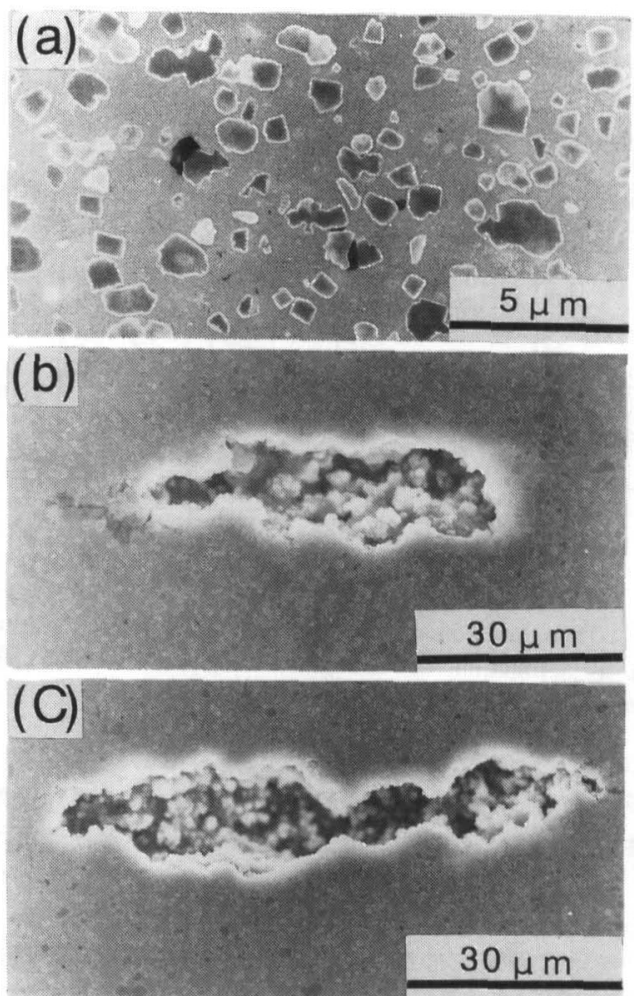

Fig.7 Cavity morphologies in the $\mathrm{Si}_{3} \mathrm{~N}_{4} / 6061 \mathrm{Al}$ composite for the $30 \%$ volume fraction of reinforcement pulled to strains of (a) 0.2 (b) 0.78 and (c) 1.04 at $823 \mathrm{~K}$.

\%Vf材の方が実験範囲内で常に少し低い値を示したも のの增加率は両材ともにほぼ同じ程度で，強化材含有 率の空洞量に及ぼす影響は小さかった

2.空洞は両材ともマトリックスと強化材との界面に

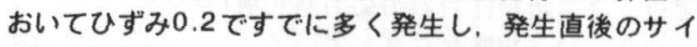
ズは大体直径 $1 \mu \mathrm{m}$ 以下であった その後の成長は遅く， 大多数の空洞は2 $\mu \mathrm{m}$ 以下であった。しかし、一部に塑 性支配による10 $\mu \mathrm{m}$ をこる大きい空洞が見られた。

\section{文献}

1) T.G.Nieh, C.A.Henshal and J.Wadsworth: Scripta Metall.,18(1984)1405.

2) H.Iwasaki, M.Mabuchi and K.Higashi: Proc.Advanced Composites'93, ed.T.Chandra and A.D.Dhingra, TMS, (1993) 1093.

3) T.G.Nieh, J.Wadsworth, T.Imai: Scripta Metall. Mater. , 26(1992)703.

4) M.Mabuchi, K.Higashi :Metall.Trans,JIM.,35-6(1994) 399.

5) H.Iwasaki, M.Takeuchi, T.Mori, M.Mabuchi and K.Higashi: Scripta Metall. Mater., 31-3 (1994)255. 